\title{
Dylan and Alexander
}

\section{Anastasia Parker}

Dylan rubs his eyes and sniffs. He can smell eggs and toast cooking downstairs. The sun shines through his window. He smiles and sits up in his bed. It's going to be a happy day.

He throws open his covers and jumps into his Thomas the Tank Engine slippers. His feet patter downstairs and he sneaks to the table. Slipping between the chair and table, he quietly lifts himself up onto his seat. Mummy turns from the stove and jumps up in surprise.

'Where did you come from?'

'Magic, Mummy'.

She laughs and places a piece of buttered toast on a plate in front of him. She tosses eggs onto the toast then scribbles tomato sauce over the lot in the shape of a smiley face. Dylan giggles and smiles at his mother. She places another plate at the empty seat next to Dylan. 'Hope you like it, Alexander.' 
Dylan shakes his head. 'No, it's sunny, Mummy. He's not here today, he murmurs through a mouthful of toast.

Mummy pinches an egg from the opposite plate. 'More for me then,' she laughs.

Dylan frowns, but soon laughs as well. Alexander wouldn't mind.

Dylan squirms as Mummy combs his hair and laces his shoes. 'Where are we going, Mummy?'

'We're going to befriend some bears and eat porridge with Goldilocks.'

Dylan smiles as he takes his mother's hand and steps out into the warm sun.

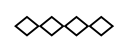

Dylan rolls over and squints as his sleepy eyes try to look out the window. There are dark clouds rolling through the sky and heavy rain falling on the thin roof. No aromas from cooking downstairs waft through his room. He sighs. Alexander sits beside the bed.

'Morning, Alexander.'

Alexander smiles and waves.

Dylan puts on his slippers and walks downstairs, Alexander by his side.

Mummy's eyes are leaky again. Dylan tells her she should go see Doctor Kennedy and get her eyes fixed, to stop them leaking so much. She smiles, then returns to stirring her drink and staring out the window. Dylan gets two bowls from the cupboard and places them on the table. He shakes the cereal into the bowl and pours the milk. He slops a little on the table, but Mummy doesn't mind. 
She isn't really there anyway. Dylan sits in his chair and Alexander sits next to him. Dylan slurps milk from his spoon. Alexander sits, smiling and watching, not touching his bowl. Mummy sits on the other side with her yucky brown drink and swallows a happy pill. It is a sad day.

Dylan finishes his breakfast. 'You finished?' he asks Alexander.

Alexander nods and leaves the table, his bowl still full.

'Can me and Alexander watch TV, Mummy?'

Mummy nods with water still dribbling down her cheeks. Dylan wraps his arms around her waist and smiles up at her. She sniffs and looks down. She kisses his forehead. Alexander hugs her too, but she doesn't move. Dylan goes to the door of the lounge and looks back at his mummy. She is staring sadly into her glass. Alexander runs to the lounge and waves Dylan over, pointing to the Wiggles video. Dylan smiles, runs to him and turns on the TV.

Dylan wakes up wrapped in his Wiggles blanket. It's raining again. He can hear Mummy crying loudly in her room. Alexander puts his hands over Dylan's ears and smiles. They can still hear the crying, it makes Dylan sad. Alexander begins to sing the Shaky Shaky song from the Wiggles tape, and encourages Dylan to join him. 'Hey there, shaky shaky. Shaking is fun to do. Hey there, shaky shaky. I wanna shake with you.' They jump out of bed, singing and imitating the actions, blocking out the cries from down the hall.

\section{$\infty \infty$}

The sun shines through Dylan's window. He can smell eggs cooking. Dylan puts on his slippers and goes downstairs. Alexander 
isn't there today, but that's OK. Mummy sits at the table smiling with breakfast on the table. It is a happy day.

'What are we doing today?'

'Once you've eaten and gotten dressed we'll go to the video shop and you can choose anything you want to borrow.

Dylan mashes his egg into his toast with his fork. 'Will they have more Wiggles?'

Mummy ruffles his hair smiling, 'I'm sure they will.'

$\infty \infty$

It's been raining for days now. Dylan sits in front of the TV with Alexander, Mummy is still in bed. It is the afternoon and cereal bowls still sit on the table. Dylan's has a little milk in the bottom, but Alexander's is full. Dylan creeps to Mummy's room. He reaches for the handle but he hears Mummy crying and the smashing of glass. He moves away.

'Are you OK, Mummy?'

'Go downstairs, Dylan. You watch Wiggles with Alexander.'

Alexander beckons Dylan downstairs but he stays by the door.

'Can I help, Mummy?'

'Mummy doesn't need help, Dyl, I'm fine. Go watch TV, OK?'

Alexander takes Dylan's hand and they go downstairs.

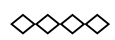

Sun shines through the window. It's a happy day. Dylan sits up, Alexander sits on the end of his bed, smiling.

'Why are you here today? It's sunny'. Dylan sniffs. He can't smell 
toast.

'Where's Mummy? Why isn't she cooking breakfast? Isn't she happy today?'

Alexander's smile fades.

Dylan is worried. He runs to Mummy's room and knocks on the door. She doesn't answer. 'Mummy? Are you OK? It's sunny today'. Dylan opens the door. She doesn't look well. She is very white. An empty bottle of happy pills lies on the floor near the bed. 'Mummy? Why are you still sleeping? Are you sick?' Dylan creeps closer.

Alexander takes Dylan's hand and smiles.

'Why do we need to go? What about Mummy? Will she be OK?'

Alexander nods. They leave the room.

A policeman is downstairs. The lady next door is there, too. Dylan is scared, but Alexander squeezes his hand. The sun shines through the open door.

'Isn't it a happy day?'

Alexander's smile fades.

Dylan doesn't understand. 